\section{Diabetes mellitus in patients with mental disorders: Prevalence and associated factors}

\author{
Desola Shakirah Owolabi, 1,2 \\ Baffa Adamu Gwaram, ${ }^{1}$ \\ Femi Lukman Owolabi, ${ }^{1}$ \\ Musa Usman Umar, ${ }^{1}$ \\ Muhammad Murtala Umar, ${ }^{2}$ \\ Abdullahi Musbahu, ${ }^{2}$ Abdullahi Shehu, ${ }^{1}$ \\ Suleiman Yahaya Isah ${ }^{1}$ \\ ${ }^{1}$ Bayero University, Kano State; ${ }^{2}$ Aminu \\ Kano Teaching Hospital, Kano State, \\ Nigeria
}

\begin{abstract}
People with mental disorders have co-
\end{abstract} morbid physical illnesses, particularly an increased risk of diabetes mellitus (DM), found in many psychiatric disorders; schizophrenia, major depression and bipolar disorder. This elevated risk is associated with increased mortality, more so, as treatment of such medical conditions is not easily accessible by people with mental disorders. The aim of the paper is to determine the prevalence and associated factors for DM in patients with mental disorders in Kano, northwest Nigeria. In this cross-sectional study, one hundred and fifty-seven consecutive patients, aged 18 years and above, attending the outpatient psychiatry clinic of Aminu Kano Teaching Hospital were recruited. Sociodemographic and clinical characteristics questionnaires were completed. Height, weight and blood pressure were measured. Subsequently $3 \mathrm{~mL}$ of blood was taken using aseptic venepuncture technique and glycated hemoglobin (HbA1c) levels were detected, with a cutoff point of $6.5 \%$ used for diagnosis of DM. The age of the patients ranged between 1879 years with a mean $(\mathrm{SD})$ of $35.5( \pm 10.6)$ years. Majority of the patients $91(58 \%)$ were female. Schizophrenia was the most common diagnosis $(37.6 \%)$ The prevalence of DM was $24.2 \%$.A statistically significant association was found between DM and age $(\mathrm{P}=0.021)$, duration of illness $(\mathrm{P}=0.016)$ and diagnosis of schizophrenia $(\mathrm{P}=0.027)$. $\mathrm{DM}$ is common in patients with mental disorders. Associated factors for DM in people with mental disorders include increasing age, prolonged duration of illness and a diagnosis of schizophrenia, the latter being an independent predictor of DM in people with mental disorders.

\section{Introduction}

People with mental disorders tend to have co existing medical conditions which may go unrecognized and untreated. ${ }^{1}$ This co-morbidity with physical illness is associated with increased morbidity and lower life expectancy than the general population. ${ }^{2}$ More so, evaluation and treatment of medical conditions may not be easily within reach of people with severe mental illnesses (SMI) ${ }^{2-4}$ A study that examined rates of physical illness in patients with mental disorders found that $43 \%$ of the participants had at least one physical disease, with diabetes mellitus(DM) being the second most common disorder, accounting for $5.4 \%$ of the disorders. ${ }^{1}$ Other reports have also confirmed that patients with severe mental disorders are at an increased risk of developing DM; people with schizophrenia are two to four times more likely to have DM than the general population with schizophrenia being an independent risk factor for the development of DM. ${ }^{5,6}$ Major depression and bipolar disorder are also associated with increased risk of $\mathrm{DM},{ }^{7,8}$ with the risk of developing DM as high as $60 \%$ in people with major depression. ${ }^{9}$

The relationship between DM and mental disorders is bidirectional and complex with attendant implications such as impaired quality of life, increased cost of care and poor treatment adherence amongst others. ${ }^{10-12}$ Reasons for the development of DM amongst other cardiovascular disease risk factors in this group of people include genetic factors, unhealthy diets which are high in fats, low in fiber, sedentary lifestyle, disease specific effects and side effects of treatment. Also, the increased risk may be attributed to an increase in traditional risk factors for DM, such as family history of DM and obesity. ${ }^{13}$ Other factors include the use of psychoactive substances such as tobacco as studies have shown that cigarette smoking could be a modifiable risk factor for the development of DM. ${ }^{14,15}$ Findings from the Clinical Antipsychotic Trials of Intervention Effectiveness(CATIE) study showed that patients with schizophrenia are more likely to smoke than the general population. Sixty eight percent of the patients in the study smoked cigarette compared to $35 \%$ of age matched controls. In the same study, the rates of DM in patients with schizophrenia was higher when compared with controls. ${ }^{16}$

Despite studies implicating psychotropic medications in the etiology of DM in people with mental disorders as a result of adverse effects such as metabolic derangements and weight gain, ${ }^{17,18}$ which are known risk factors for DM, a study has
Correspondence: Desola Shakirah Owolabi, Department of Psychiatry, Aminu Kano Teaching Hospital, Bayero University, PMB 3452, Kano, Nigeria.

E-mail: edesola@yahoo.com

Key words: Diabetes mellitus, mental disorders, associated factors.

Contributions: the authors contributed equally.

Conflict of interest: the authors declare no potential conflict of interest.

Funding: none

Received for publication: 19 July 2018.

Revision received: 17 October 2018.

Accepted for publication: 17 October 2018.

This work is licensed under a Creative Commons Attribution NonCommercial 4.0 License (CC BY-NC 4.0).

CCopyright D. Shakirah Owolabi et al., 2018 Licensee PAGEPress, Italy

Pyramid Journal of Medicine 2018; 1:5

doi:10.4081/pjm.2018.5

shown that such metabolic abnormalities were present in drug naive patients, pointing to these features being inherent in people with schizophrenia but their impact only worsened by the antipsychotic medications. ${ }^{19}$

Considering the high prevalence and implications of DM among people with mental disorders, a study investigating the prevalence and the nature of association between DM and mental disorders is of utmost importance.

This study thus aims to determine the prevalence and associated factors for DM in people with mental disorders.

\section{Materials and Methods}

\section{Methodology}

This cross-sectional study was carried out at the outpatient psychiatry clinic of Aminu Kano Teaching Hospital (AKTH), Kano, Northwestern Nigeria. One hundred and fifty-seven consecutive consenting patients aged 18years and above were recruited. Diagnosis of mental disorders was done using the Diagnostic and Statistical Manual of mental disorders-fifth edition (DSM-5).

All the participants had their information taken and recorded in the proforma designed specifically for this study. Subsequently basic clinical examination including height, weight and blood pressure was done 
Finally, participants were directed to the department of Medicine research laboratory of the same hospital where $3 \mathrm{~mL}$ of blood using aseptic venepuncture technique was obtained using a $5 \mathrm{mls}$ syringe and transferred to a di-potassium ethylene diaminetetraacetic acid (EDTA) bottle. Packed cell volume (PCV) was done using the microhematocrit method by an experienced laboratory technician.

The glycated hemoglobin (HbA1c) test was carried out by an experienced laboratory scientist using the LabonaCheck ${ }^{\mathrm{TM}}$ technique according to manufacturer's specifications after excluding participants that have packed cell volume (PCV) of less than $30 \%$ or more than $60 \%$. The Labona $\mathrm{Check}^{\mathrm{TM}} \mathrm{A} 1 \mathrm{c}$ is a boronate affinity assay in which PCV lower than $30 \%$ or higher than $60 \%$ may give inaccurate results. It has precision comparable to that of high-performance liquid chromatography (HPLC). A cut-off point of $6.5 \%$ was used for the diagnosis of DM. ${ }^{20}$ Patients with a positive result were further subjected to random blood sugar (RBS) test using Accuchek Advantage glucometer according to manufacturer's instructions.

Ethical clearance was obtained from research ethics committee of Aminu Kano Teaching Hospital (AKTH).

\section{Data analysis}

All the data generated were collated, checked and analyzed using a computer based Statistical Package for the Social Sciences (SPSS) version 16.0. Quantitative variables are described using mean and standard deviation (SD) and the independent sample $\mathrm{T}$ test was used to compare means. Qualitative variables are presented as percentages. The non-parametric test $\mathrm{X}^{2}$ was used to compare proportions where appropriate. A confidence interval of $95 \%$ was used and a P value of $<0.05$ is considered significant.

\section{Results}

The age of the patients ranged between 18-79 years with a mean (SD) of 35.5 $( \pm 10.6)$ years. Majority of the patients 91 $(58 \%)$ were female while only $14(8.9 \%)$ were unemployed. Details of sociodemographic characteristics of patients is showed in Table 1. Schizophrenia was the most common diagnosis accounting for $37.6 \%$ of diagnosis, while major depression, bipolar disorder, somatic symptom disorder and anxiety disorder accounted for $32.5 \%$, $19.7 \%, 5.7 \%, 4.5 \%$ respectively. The frequency of various psychotropic drugs used is as follows, antipsychotics only $31.4 \%$, antidepressant only $29.5 \%$, combined antipsychotic and mood stabilizer $21.8 \%$, combined antipsychotic and antidepressant $14.1 \%$, mood stabilizer only $3.2 \%$. Mean (SD) duration of illness was $7.26( \pm 5.95)$ years. Thirty-six $(22.9 \%)$ patients were obese while only 7 (4.5\%) smoked cigarette. Family history of DM was present in 50 $(32 \%)$ patients.

The prevalence of DM was $24.2 \%$.The mean age of patients with DM (SD) was higher at $38.95( \pm 11.43)$ years when compared to $34.41( \pm 10.09)$ for the non-diabetic patients (Table 2). A statistically significant association was found between DM and age $(\mathrm{P}=0.021)$. There was no statistically significant association between DM and gender $(\mathrm{P}=0.253)$, family history of $\mathrm{DM}(\mathrm{P}=0.967)$, cigarette smoking $(\mathrm{P}=0.238)$, obesity $(\mathrm{P}=0.448)$ (Table 2).

The mean (SD) duration of illness of diabetic patients was higher at 9.26 ( \pm 7.96$)$ years compared to $6.62( \pm 5.01)$ years for non-diabetics (Table 2), and it showed a statistically significant association between $\mathrm{DM}$ and duration of illness $(\mathrm{P}=0.016)$.

No statistically significant association was found between diagnosis and DM, however when schizophrenia was dichotomized with other disorders (Table 2), individuals with schizophrenia were two times more likely to have DM, odds ratio (OR) 2.279 [95\% CI: 1.084,4.791].

Drug type had no significant association with DM $(\mathrm{P}=0.083)$. Further separation of typical/atypical antipsychotics from other psychotropic drugs also yielded no significant association $(\mathrm{P}=0.168)$.

However, after adjusting for confounders using logistic regression analysis, only a diagnosis of schizophrenia was found to be an independent predictor of DM in people with mental disorders $(\mathrm{P}=0.015)$.

\section{Discussion}

The prevalence of DM obtained in our study $(24.2 \%)$ is higher compared to findings in some other studies. ${ }^{1,21}$ This could be attributed to the fact that majority of our patients had schizophrenia, with studies reporting prevalence rate of up to $25 \%,{ }^{22,23}$ and an increased risk of DM compared to other mental disorders. ${ }^{1}$ Studies assessing prevalence of DM in people with mental disorders have done so by detecting fasting blood sugar levels (FBS), ${ }^{1,21}$ this could also account for the difference in prevalence rates as day to day variation in blood sugar levels may alter the result. The mean age of patients with DM was higher than for nondiabetics in the index study, this conforms to reports of a previous study that the risk of DM increased with age. In the study, the prevalence of DM increased from $0 \%$ in individuals younger than 50 years, to $12.9 \%$ in those between 50 and 59 years of age and to $18.9 \%$ in participants aged $60-69$ years. ${ }^{22}$ Furthermore our study showed a statistically significant association between DM and age, this has similarly been demonstrated by another study. ${ }^{24}$ Although no significant association was found between DM and gender, men were more likely (29\%)to have diabetes than women (21\%).This is similar to findings in a controlled study in which $8.8 \%$ of the $12.8 \%$ patients that were diabetic were males. ${ }^{21}$ Other researchers have also debated a higher incidence of DM in

Table 1. Socio-demographic characteristics of patients.

\begin{tabular}{lcc} 
Characteristics & Frequency $(\mathbf{n})^{*}$ & Percentage (\%) \\
Age (Mean \pm SD) & $35.5 \pm 10.6 y e a r s$ & \\
Gender & 66 & 58 \\
$\quad$ Male & 91 & \\
Female & & 62.4 \\
\hline Marital status & 98 & 26.1 \\
$\quad$ Married & 41 & 11.4 \\
Single & 18 & \\
Divorcee/Widow & & 12.7 \\
Occupation & 20 & 32.5 \\
Student & 51 & 14.6 \\
Housewife & 23 & 17.8 \\
Trader & 28 & 8.9 \\
Civil servant & 14 & 13.4 \\
Unemployed & 21 & \\
Others & & 31.8 \\
\hline Family history of DM & 50 & 68.2 \\
$\quad$ Present & 107 & \\
Absent &
\end{tabular}

${ }^{*}$ Number of patients for categorical variables or mean for continuous variables. 
men than women. ${ }^{25} \mathrm{~A}$ retrospective review assessing prevalence of DM in a group of adults with severe mental disorders found a significant association between DM and family history of DM, such association was not seen in our study. Nonetheless, a family history of DM has been known to be a risk factor for DM and may increase the risk of developing DM in people with schizophrenia up to three-fold. ${ }^{24}$ Furthermore, family history of DM is significantly higher even among the first-degree relatives of patients with schizophrenia. ${ }^{26}$

Although cigarette smoking has been identified as a modifiable risk factor for development of DM, we found no significant association between cigarette smoking and DM probably because of the minute number $(4.5 \%)$ of the patients in our study who smoked cigarette.

The index study showed a longer duration of illness among diabetic patients with mental disorders compared to non-diabetics, and the association between DM and duration of illness was statistically significant. This is in concordance with the findings of a study that showed an increase in prevalence of DM from 3\% in first episode patients to $16.5 \%$ in patients with duration of illness of more than 20 years. ${ }^{19}$

With respect to diagnosis, patients with schizophrenia had the highest rate of DM $(33.89 \%)$,followed by major depression (17.65\%) and bipolar disorder (16.12\%), with people with schizophrenia having 2.3times increased risk compared to other disorders. This could be explained by the increased vulnerability to DM in people with schizophrenia as metabolic problems such as impaired glucose tolerance are suggested to be an inherent part of the disorder, ${ }^{19}$ since they are present at first episode of illness. Furthermore, some related studies have reported higher rates of DM among people with schizophrenia compared to other mental disorders, ${ }^{1,27}$ while another has found a slightly higher rate in patients with depression. ${ }^{21}$

Our study did not find a significant association between DM and psychotropic drug use even when typical/atypical antipsychotics were separated from other psychotropic medications. This is similar to findings elsewhere in which diabetes was not found to be related to antipsychotic drug use. ${ }^{22}$ Another study assessing new cases of DM did not find a significant association between atypical and typical antipsychotics. ${ }^{28}$ Although it is difficult to separate the direct effects of antipsychotic medications from the primarily increased risk of DM posed by the mental disorder itself, ${ }^{13}$ studies have demonstrated increased predisposition to DM following antipsychotic drug use, particularly the second generation antipsychotics (SGA). ${ }^{29,30}$

Several mechanisms are thought to be involved in development of DM in people with mental disorders. One of such mechanisms is drug induced weight gain; however, the current study found no significant association between DM and obesity. This may not be farfetched as an interplay of factors determine the extent to which weight gain may be associated with occurrence of $\mathrm{DM}$, with the duration of weight gain and the length of time the patient took the weight inducing psychotropic drugs being important factors. Many psychotropic drugs have the tendency to cause weight changes, among which the second generation anti-

Table 2. Factors associated with diabetes mellitus (DM) in patients with mental disorders.

\begin{tabular}{|c|c|c|c|}
\hline Characteristics (total) & DM, yes (\%) & DM, no (\%) & P value \\
\hline Age (mean \pm SD) & $39.0 \pm 11.4$ & $34.4 \pm 10.1$ & $0.021^{*}$ \\
\hline Duration of illness (mean \pm SD) & $9.3 \pm 8.0$ & $6.6 \pm 5.0$ & $0.016^{*}$ \\
\hline $\begin{array}{l}\text { Gender } \\
\quad \text { Male (66) } \\
\text { Female (91) }\end{array}$ & $\begin{array}{l}19(28.8) \\
19(20.9)\end{array}$ & $\begin{array}{l}47(71.2) \\
72(79.1)\end{array}$ & 0.253 \\
\hline $\begin{array}{l}\text { Family history of DM } \\
\text { Present (50) } \\
\text { Absent (107) }\end{array}$ & $\begin{array}{c}12(24) \\
26(24.3)\end{array}$ & $\begin{array}{c}38(76) \\
81(75.7)\end{array}$ & 0.967 \\
\hline $\begin{array}{l}\text { Obesity } \\
\text { Present (36) } \\
\text { Absent (121) }\end{array}$ & $\begin{array}{l}7(19.4) \\
31(25.6)\end{array}$ & $\begin{array}{l}29(80.6) \\
90(74.4)\end{array}$ & 0.448 \\
\hline $\begin{array}{l}\text { Cigarette smoking } \\
\text { Present (7) } \\
\text { Absent (150) } \\
\end{array}$ & $\begin{array}{c}3(42.9) \\
35(23.3)\end{array}$ & $\begin{array}{c}4(57.1) \\
115(76.7)\end{array}$ & 0.238 \\
\hline $\begin{array}{l}\text { Diagnosis } \\
\text { Schizophrenia (59) } \\
\text { Major depression (51) } \\
\text { Bipolar disorder (31) } \\
\text { Anxiety disorder (7) } \\
\text { Somatic symptom disorder (9) }\end{array}$ & $\begin{array}{l}20(33.9) \\
9(17.6) \\
5(16.1) \\
2(28.6) \\
2(22.2)\end{array}$ & $\begin{array}{l}39(66.1) \\
42(82.4) \\
26(83.9) \\
5(71.4) \\
7(77.8)\end{array}$ & 0.248 \\
\hline $\begin{array}{l}\text { Diagnosis dichotomy } \\
\text { Schizophrenia (59) } \\
\text { Non Schizophrenia (98) } \\
\end{array}$ & $\begin{array}{l}20(33.9) \\
18(18.4)\end{array}$ & $\begin{array}{l}39(66.1) \\
80(81.6)\end{array}$ & $0.027^{*}$ \\
\hline $\begin{array}{l}\text { Drug type } \\
\text { Antipsychotic (49) } \\
\text { Mood stabilizer (5) } \\
\text { Antidepressant (46) } \\
\text { Mood stabilizer + antipsychotic (34) } \\
\text { Antidepressant + antipsychotic (22) }\end{array}$ & $\begin{array}{l}16(32.7) \\
2(40) \\
6(13) \\
6(17.6) \\
8(36.4)\end{array}$ & $\begin{array}{c}33(67.3) \\
3(60) \\
40(87) \\
28(82.4) \\
14(63.6)\end{array}$ & 0.083 \\
\hline $\begin{array}{l}\text { Drugs subgroups } \\
\text { Typical antipsychotics (59) } \\
\text { Atypical antipsychotics(46) } \\
\text { Other drugs(52) }\end{array}$ & $\begin{array}{l}18(30.5) \\
12(26.1) \\
8(15.4)\end{array}$ & $\begin{array}{l}41(69.5) \\
34(73.9) \\
44(84.6)\end{array}$ & 0.168 \\
\hline
\end{tabular}


psychotics (SGA) are well studied and known to cause weight gain of greater than $7 \% .{ }^{31}$ However, some of the first generation antipsychotics (FGA) such as chlorpromazine also have a high risk of weight gain. ${ }^{17}$ Furthermore, significant individual and inter drug variation in weight change seems to occur, with children and adolescent at high risk of significant weight gain ${ }^{32}$ and SGA like clozapine, olanzapine posing more risk than others. ${ }^{33}$ Apart from inducing weight gain, antipsychotics may also alter insulin secretion, with subsequent development of DM. ${ }^{34-38}$

Similarly, mood stabilizers such as lithium and sodium valproate are also implicated in weight gain and impaired glycemic control, ${ }^{33}$ while antidepressants are known to have a modest association, with an increased risk of DM almost two-fold with long term use. ${ }^{39}$

Overall, it seems the traditional risk factors for DM supersede the risks posed by antipsychotics in the etiology of DM in patients with mental disorders. ${ }^{13}$

Despite the findings above, our study had some limitations; it was hospital based hence findings may not be generalizable to community populations. Another limitation is the use of point of care (POC) machines (using labonacheck as against HPLC and glucometer as against laboratory methods). We also did not study duration of drug use; this could have influenced our result on the association between psychotropic drug use and DM. The strength of the study however, lies in our method of detection of DM by measuring HbAlc levels which detects sugar levels over the past three months and thus eliminates the bias that occurs with FBS due to day to day fluctuations in blood sugar levels.

\section{Conclusions}

In conclusion, the prevalence of DM in people with mental disorders is high. Factors found to be significantly associated include increasing age, prolonged duration of illness and a diagnosis of schizophrenia, which is also found to be an independent predictor of DM in people with mental disorders.

This high prevalence calls for vigilance in monitoring blood glucose levels of patients with mental disorders, particularly those with schizophrenia.

\section{References}

1. Uwakwe R, Modebe I, Njelita I, et al. Rates of Physical Illness in Patients with Mental Disorders seen at Nnewi, Nigeria. Orient J Med 2013;25:24-31.

2. Fleischhacker WW, Cetkovich-Bakmas M, De Hert M, et al. Cormorbid somatic illnesses in patients with severe mental disorders: clinical, policy and research challenges. J Clin Psychiatry 2008;69: 514-9.

3. Druss BG. Improving medical care for persons with serious mental illness: challenges and solutions. J Clin Psych 2007;68:40-4.

4. Leucht S, Burkard T, Henderson J, et al. Physical illness and schizophrenia. Acta Psychiatr Scand 2007;116:317-33.

5. Expert Group. Schizophrenia and Diabetes 2003. Expert Consensus Meeting, Dublin 3-4 October 2003. Br J Psychiatry Suppl 2004;47:S112-4.

6. Holt RIG, Bushe C, Citrome L. Diabetes and schizophrenia 2005: are we any closer to understanding the link?. J Psychopharmacol 2005;19:5665.

7. Eaton WW, Armenian H, Gallo J, et al. Depression and risk for onset of type II diabetes. A prospective populationbased study. Diabetes Care 1996;19: 1097-102.

8. McIntyre RS, Konarski JZ, Misener VL, Kennedy SH. Bipolar disorder and diabetes mellitus: epidemiology, etiology, and treatment implications. Ann Clin Psychiatry 2005;17:83-93.

9. Mezuk B, Eaton W, Albrecht S, Golden S. Depression and type 2 diabetes over the lifespan: a meta-analysis. Diabetes Care 2008;31:2383-90.

10. Goldney RD, Phillips PJ, Fisher LJ, Wilson DH. Diabetes, depression, and quality of life: a population study. Diabetes Care 2004;27:1066-70.

11. Hutter N, Schnurr A, Baumeister H. Healthcare costs in patients with diabetes mellitus and comorbid mental disorders-a systematic review. Diabetologia 2010;53:2470-9.

12. Gonzalez JS, Safren SA, Cagliero E, et al. Depression, self care, and medication adherence in type 2 diaabetes:relationships across the full range of symptom severity. Diabetes Care 2007;30: 2222-7.

13. De Hert M, Dekker JM, Wood D, et al. Cardiovascular disease and diabetes in people with severe mental illness position statement from the European Psychiatric Association (EPA), supported by the European Association for the Study of Diabetes (EASD) and the European Society of Cardiology (ESC). European Psychiatry 2009;24:412-24.

14. Foy CG, Bell RA, Farmer DF, et al. Smoking and incidence of diabetes among U.S adults: Findings from the Insulin Resistance Atherosclerosis Study. Diabetes Care 2005;28:2501-7.

15. Willi C, Bodenmann P, Ghali WA, et al. Active smoking and the risk of type 2 diabetes: a systematic review and metaanalysis. JAMA 2007;298:2654-64.

16. Goff DC, Sullivan LM, McEvoy JP, et al. A comparison of ten-year cardiac risk estimates in schizophrenia patients from the CATIE study and matched controls. Schizophr Res 2005;80:45-53.

17. Allison DB, Mentore JL, Heo M, et al. Antipsychotic-induced weight gain: a comprehensive research synthesis. Am J Psychiatry 1999;156: 1686-96.

18. Allison DB, Newcomer JW, Dunn AL, et al. Obesity among those with mental disorders: a National Institute of Mental Health meeting report. Am J Prev Med 2009;36:341-50.

19. De Hert M, van Winkel R, Van Eyck D, et al. Prevalence of diabetes, metabolic syndrome and metabolic abnormalities in schizophrenia over the course of the illness: a cross-sectional study. Clin Pract Epidemiol Ment Health 2006; $2: 14$.

20. WHO. Use of glycated haemoglobin (HbAlc) in the diagnosis of diabetes mellitus. Report of a World Health Organization Consultation. Diabetes Res Clin Pract 2011;93:299-309.

21. Olatunbosun SY, Musa MA, Edward IU, et al. Prevalence of Diabetes Mellitus among Psychotropic Drug Naïve Patients with Psychiatric Disorders at Federal Neuro-Psychiatric Hospital Barnawa, Kaduna. Int Neuropsychiatr Dis J 2015;4:145-52.

22. Mukherjee S, Decina P, Bocola V, et al. Diabetes mellitus in schizophrenic patients. Compr Psychiatry 1996;37:6873.

23. Dixon L, Weiden P, Delahanty J, et al. Prevalence and correlates of diabetes in national schizophrenia samples. Schizophr Bull 2000;26:903-12.

24. Lamberti JS, Crilly JF, Maharaj K, et al. Prevalence of Diabetes Mellitus Among Outpatients with Severe Mental Disorders Receiving Atypical Antipsychotic Drugs. J Clin Psychiatry 2004:65:702-6.

25. Sandeep V, Rodney A, Kenneth M. Impact of diabetes on workforce participation. Health Serv Res 2004;39:165370.

26. Lamberti J, Crilly J, Maharaj K. Prevalence of adult-onset diabetes among out-patients receiving anti-psychotic drugs. Schizophr Res 2003;60: S360.

27. Codami T, Cross M. Psychiatric co- 